\section{Edycaçäa

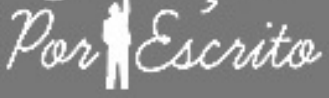

ARTIGO

\section{Editor}

Maria Inês Côrte Vitoria PUCRS, RS, Brasil

\section{Equipe Editorial}

Pricila Kohls dos Santos PUCRS, RS, Brasil

Marcelo Oliveira da Silva PUCRS, RS, Brasil

Carla Spagnolo

PUCRS, RS, Brasil

Rosa Maria Rigo

PUCRS, RS, Brasil

\title{
Escritos outros, poemas intermináveis: vida, pesquisa e educação
}

\author{
Other writings, interminables poems: life, research and education
}

\author{
Dinamara Garcia Feldens ${ }^{a}$ \\ Anthony Fábio Torres Santana ${ }^{b}$ \\ José Laerton Santos da Silvac
}

RESUMO: A palavra é líquida. Ela invade, perpassa e fere. É ela quem odeia ou ama a vitalidade do ar entrando nos pulmões. Ela implode. Arranca. Desola e sequestra. É ela que aterra as olheiras dos vulcões. Quimera alada. É ela quem dança, não dançarino. É ela quem escreve, não o escritor. É ela quem serpenteia pelo corpo das serpentes. Caverna de figuras pictóricas. Gotículas invisíveis que vem nos visitar de madrugada. Repentes amarelos. Sonhos guarnecidos. Figuras turvas na linha do horizonte. Uivos medonhos, risadas tristes, cantos de dor... Qual o real valor de nossas produções? Qual o grau de envolvimento estamos dispostos a ter com elas? Qual o real impacto de nossas produções na realidade que nos cerca? Como nós, estudantes, pesquisadores, e teóricos das ditas ciências humanas estamos comprometidos com mudanças nesta realidade, que por vezes, tanto criticamos? Escrever é sempre um ato poético. Escrevemos na tentativa de eternizar o que não se vê. De captar o que nos acontece. Às vezes conseguimos fazer isso por um momento. Às vezes tudo nos escapa... Este ensaio propõe uma reflexão sobre a produção acadêmica. E vai à contramão do que tradicionalmente se entende por "escrita acadêmica", propondo pensar sobre a construção de uma escrita-vida. Baseando-se em conceitos filosóficos de Gilles Deleuze, articula a ideia de escrita e produção acadêmico-científica para se pensar nas possibilidades de uma educação produtora de novas relações com a vida que nos habita.

Palavras chaves: Educação. Produção acadêmica. Filosofia.

ABSTRACT: Words are liquid. They move, slip through, and hurts. When lungs fills with air its known there are the words to love or hate this vital movement. Words can blow and rip. It's like they desolate and kidnap. Words can cover volcanos. By the side of the reverie. Words can dance, not a dancer. Words writes, not a writer. They are the pieces that wanders crossing the body of snakes. Pictorial cave figures that in the invisible midnight come to visit us. Like yellowish happenings. Kept dreams. Figures on the fog. Howls hideous, sad laughter, music from pain ... What is the real value of our productions? How much are we involved and willing to be commited with them? What is the real impact of our productions in the reality around us? How much committed are we,

a Doutora em Educação, Universidade Tiradentes - UNIT. < dfeldens@hotmail.com>.

b Doutorando em Educação, Pontifícia Universidade Católica do Rio Grande do Sul - PUCRS. < afabiotorres@hotmail.com>. c Graduando em Psicologia, Universidade Tiradentes - UNIT. <laerton@outlook.com>. 
from university, to change reality that sometimes we criticize? Writing is always a poetic act. Written in an attempt to perpetuate what is not seen. To capture what happens to us. Sometimes we can do this for a moment. Sometimes it escapes us ... This essay proposes a reflection about the academic production, proposing to think about building a writting-life. Based on Gilles Deleuze concepts, which leads to an idea of writting and production, academic-scientific to think about possibilities of an education that can be a producer of new relations with life that lives in us.

Keywords: Education. Academic research. Philosophy.

Teve mesmo que sentir algo a mais: toda sua existência, com toda a sua beleza e sua medida, repousava sobre um abismo oculto de dor e de conhecimento e o espírito dionisíaco lhe mostrava novamente o fundo do abismo. [...] O indivíduo, com toda a sua ponderação e sua medida, TYsubmergiu no esquecimento de si. [...] A desmedida se revelou verdade; a contradição, o êxtase nascido da dor falava espontaneamente de si, do coração da natureza.

(Nietzsche. O nascimento da tragédia)

\begin{abstract}
A
nossa educação parece sempre estática. Sem estar em movimento, não nos move. Educamos para que possamos continuar no mesmo lugar. Educamos para que possamos ficar na mesma cidade. Para não mudar de país. Para não mudar de eu. Educamos para identidade. Nesse contexto a experimentação de si é algo periférico, que deve ser marginalizado. Disso resulta nosso medo do corpo. Da vida, da palavra dita. Da linguagem muda. Aprendemos a ter medo do movimento. Medo do que pode o corpo, da desrazão, do inesperado.

Tradicionalmente quando se pensa em educação, costuma-se pensar em alguma coisa sem ousadia: Educação é disciplina, ficar sentando, falar baixo. Ouvir, e só falar quando lhe for permitido. Esperar a sua vez. Levantar a mão para ir ao banheiro. O corpo pode esperar, pode sempre ficar pra depois. E se alguém quer dançar? Não! Não é hora de dançar, nem de gritar, nem falar, nem de brincar, nem de viver. Temos a impressão que a vida está lá fora: fora do muro da escola, fora dos portões da universidade, a vida, pensamos, me aguarda, assim que eu sair da aula...

Enquanto pesquisadores, educadores, pensadores; enquanto seres humanos dotados de vida, quais aspectos da exuberância do mundo temos priorizado em nossas escritas? Quais territórios queremos habitar com nossas aulas? Quais afetos queremos tocar com nossas reflexões? Mal temos consciência que é em nossas escritas que se entrecruzam a ética, a política e a estética. Entrecruzam-se, e geram movimentos imprevisíveis. As linhas de fugas surgem nos movendo para intensidades outras. Colocando-nos em contato com realidades áridas e por vezes
\end{abstract}


intransmissíveis. Outras vezes intransponíveis. E em outras ainda, puro silêncio. Aqui, partimos então, do pressuposto teórico do filósofo Gilles Deleuze, de que "As pessoas são compostas de linhas muito diversas, [...] e não sabem necessariamente em que linha está, nem onde fazer passar a linha que estão em vias de traçar: numa palavra, há toda uma geografia nas pessoas, com linhas duras, linhas flexíveis, linhas de fuga, etc." (DELEUZE; PARNET, 2004, p. 21).

Estar atento à ética, à política e à estética, pode significar estar atento aos territórios nos quais nossas escritas se compõem. Às linhas que se traçam no momento mais atual. Estar atento a estes aspectos pode fazer toda diferença na experimentação de si. E na tessitura de nossos escritos.

Operar por uma marca ética na escrita significa escutar e experimentar a diferença em nós, como elaboramos nossos textos. Imprimir uma marca estética reside na possibilidade de acionar processos inventivos tanto em termos do pensar quanto do expressar, no ato mesmo em que a produção dessa escrita se realiza, aprofundando as possibilidades de nos relacionarmos ética e politicamente com aquilo que estamos produzindo. Por fim, a marca política se coloca como a possibilidade que temos em nossas atividades de produção acadêmica de imprimir forças que rivalizem com aquelas que tentam manter a ilusória experiência de nós mesmos como uma verdade, negando, portanto, nossas possibilidades de diferenciação e alteridade. (DIMENSTEIN; MACEDO, 2009)

Propomos refletir sobre uma educação que nos tire para dançar! Que nos pegue pela cintura e nos eleve ao alto! Ao mais alto de nós! Que faça traçados por terras coloridas. Propomos refletir sobre produções acadêmicas que partam da experimentação de si como base de reflexões autênticas, que nos levem a devires outros, E aos nossos desertos, $\mathrm{E}$ ao novo, E à surpresa do mundo, E..., E...

Prezamos por uma escrita que habite os lugares bons e as poéticas da existência. Por uma educação que diga sim à vida, ao mundo e ao corpo. Uma educação que liberte o corpo. E que o leve a ser outra coisa, que o desobrigue a ser-corpo e que o corpo seja, agora, não corpo, mas a falta de fronteira, as cores que habitam o amanhecer. Uma educação que ensine o corpo a ser todas as coisas. Todos os rios. Todas as danças. Todas as dunas. E que o corpo seja então nosso deserto povoado. E que vida, educação e pensamento não sejam territórios separados. Mas que sejam territórios coabitados por nossas potências. A vida, "já não cabe nas linhas de uma existência atrelada a preceitos, pois transbordam seus limites em exercícios de potência” (DIMENSTEIN; MACEDO, 2009).

$\mathrm{O}$ intelecto nasce como forma de defesa de seres mais fracos, desenvolvido de modo a compensar sua fragilidade no mundo e fazer a espécie sobreviver. O impulso natural pela verdade se dá no medida em que nossos sentidos 
parecem não captar as informações corretas sobre a realidade e nossas percepções são acerca da própria individualidade do sujeito. "É por meio da linguagem que os homens vão se entender sobre as determinadas formas de agir dentro do rebanho e dentro da sociedade." (SOMA, F., p. 04).

A linguagem é definida á medida em que se convenciona que determinados sons, articulados de certa maneira designam coisas que estão no mundo. O problema da convenção é o tom de verdade que ela adquire e o tom de mentira que adquirem outros modos de expressão.

[...] o que se passa com aquelas convenções da linguagem? São talvez fruto do conhecimento, do senso de verdade: as designações e as coisas se recobrem? É a linguagem a expressão adequada de todas as realidades? (NIETZSCHE, 2005, p. 55)

A 'coisa em si' é completamente incaptável, não está acessível ao intelecto. O que sabemos é a relação da 'coisa' com o homem, sua utilidade. O olhar para os inúmeros componentes maquínicos de subjetivação nos leva a refletir sobre a heterogeneidade que é a produção da subjetividade. Estas comportam dimensões semióticas que escapam da linguística, conduzindo a produção de imagens e evitando o pensamento mecanicista. A criação de novos universos referenciais talvez nos faça sair do período midiático opressivo atual, re-significando e re-singularizando a utilização destas mídias.

$\mathrm{Na}$ contemporaneidade, faz-se mais que urgente, buscar os pontos de tensão de nossa educação e fazer deles nossas moradas. Habitar os meios entre o silêncio e a palavra, entre a ordem e caos, entre o corpo e o nada. Não fixar-se, mas eleger uma existência nômade. O horizonte a perder de vista. Outrar-se. Outros, outros e tantos outros. Buscar um "permanente outramento de si - ou abertura, fenda, para o indeterminado, o instável, o imprevisível." (DIMENSTEIN; MACEDO, 2009).

Este movimento pressupõe uma desconexão com a ideia de identidade que tanto nos persegue. Um abandono permanente do eu. Algo como uma eterna partida. Partir de si, seguir um fluxo. Fluxos de desejos. De intensidades. De velocidades. Conexões de fluxos. "O desejo não para de efetuar o acoplamento de fluxos contínuos e de objetos parciais essencialmente fragmentários e fragmentados. O desejo faz correr, flui e corta." (DELEUZE; GUATARRI, 2010, p. 16).

Nesta trajetória, seguindo fluxos, experimentando a si e o mundo em um só movimento, e sentindo a vida na forma mesmo em se apresenta a nós, pode-se então vislumbrar uma escrita potência, desejante, Sem Cabimento... 
Queria escrever todas as plantas e pessoas. todos os rios.

os muros, as cores, os homens, as senhoras de idade.

as caixas de correio, os espanhóis.

os olhos e as ruas, os tamanhos e larguras, as alturas.

as pernas, os falos, os pelos, os pulsos.

Queria escrever o ritmo,

das pedras, das estradas calçadas, das margaridas.

escrever o que manda e o que obedece.

o que cresce e o que padece de amparo.

o que afunda, o que eclode.

escrever o que não sabe.

e o que não cabe em lugar nenhum.

E viver a escrita das coisas.

não as coisas que não me cabem.

coisas e pessoas não me cabem e sem cabimento

me atravessam.

pessoas passam depressa demais entre meus poros. e vão.

eu tenho uma imagem presa na garganta.

ser gente me arranha.

quero voltar a ser palavra [...].

(VIVIANE MOSÉ) ${ }^{1}$

Escrever a si e a vida no momento mesmo em que ocorrem. Escrita-devir. Uma escrita agora, conectada com a inventividade da vida. Transbordante e ascendente. Não uma escrita travestida, figurada, que se faz de. Maquinada e indiferente, mas sim, uma escrita que tece uma "exploração de pensamentos, conhecimentos, experiências, vidas e(m) ambientes singulares e não uma metáfora [...] mas uma singularização expressa. Afirmação de uma afinidade entre pensamento e vida.” (ANDRADE; SPEGLICH, 2011).

Acreditamos, que por meio da arte, dos afectos, e das conexões com o devires intensos, a educação e o pensamento, podem ser reinventados, e mergulhados em uma nova atmosfera, dando origem a novas linhas

\footnotetext{
1 Poema retirando do site: <http://poesiaetudo.blogspot.com.br/2009/12/viviane-mose.html>, acessado em 10 abr. 2013.
} 
de fugas, que nos levarão por caminhos inesperados. Por desvios de nós. A toca do coelho. "Desvios que são possíveis empreender na busca do sentir, do apalpar e de escutar as rotas e explosões do seu próprio pensamento e invenção. [...] Experiências de desvio do que se é ou se pretendia ser." (DIMENSTEIN; MACEDO, 2009).

Se a vida é isso que sempre nos escapa, que é sempre transbordante, porque a educação, o pensamento e a escrita acadêmica teimam em confabular com coisas apequenadas e apequenantes. Com o previsto, com o mesmo. Não há lugar para o diferente na educação. Muito pelo contrário, o processo de educação vigente exibe suas disciplinas, controles e técnicas imóveis, estáticas, monocromáticas. Máquinas de captura. Aprendamos a domar a si e ao outro, e nesta "colonização aprendemos a morrer e nos matar." (FELDENS, 2008, p. 65).

Enquanto educa-se, salvo raras exceções, ignoram-se as cores do mundo, as músicas do corpo e as paisagens da vida. Ainda no século XXI, assistimos uma educação para o embotamento. Para esquecer os afetos e para lembrar que existem regras e leis que "regem" a vida. E que estas não devem ser esquecidas. Mas constantemente lembradas e seguidas. Uma educação que vai no sentido oposto de um mundo onde os fluxos de imagens são quase incomensuráveis, o real e o virtual se confundem gerando instabilidades, dissolução de distâncias e uma nova e poems xperiência de temporalidade. Mas ainda se educa para um mundo estático. Os filhos de nossa educação chegam ao mundo com um século de atraso.

Ao contrário daqueles que esperam tudo da indigestão das ideias e dos discursos - haveria muito a dizer sobre o abuso das ideias, a prostituição das palavras, o esgotamento textual da língua - em vez disso, você será julgado pela brevidade de suas intuições e discursos. [...] Outra promessa dos fragmentos: só eles sobreviverão à catástrofe, à destruição do sentido e da língua- como as moscas na queda do avião, únicas sobreviventes porque ultraleves. (BAUDRILLARD, 2000, p. 17)

Dentro desse mundo rico em estímulos, talvez seja mesmo difícil estar conectado com o que nos ocorre. Talvez seja difícil dividir a atenção e apreender o que se passa dentro e fora de nós. "Nos faltam órgãos mais sutis que possam ler a complexidade múltipla que se encontra em todas as manifestações da vida." (MOSÉ, 2011, p. 120). Talvez isso exija de nossos olhos uma forma de vê que ainda não aprendemos: uma vidência do presente. Uma vidência que nos faz

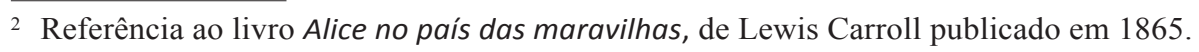


conhecer o presente em suas infinitas conexões possíveis, de modo a "enxergar" no instante mesmo em que os fatos ou os eventos se efetivam as relações prováveis e improváveis que se tecem entre o conhecido (ou o já sabido) com o desconhecido e o indeterminado. [...] Não com o objetivo de encontrar uma verdade ou a verdade das palavras, ou mesmo a verdade de sua própria poética, mas desfazer a todo instante qualquer possibilidade de rostidade que possa dar um tom ordinário à produção-experimentação. (DIMENSTEIN, MACEDO, 2009)

Assim, podemos enfim,

produzir narrativas que façam tocar nossas experiências de modo a dialogar as marcas de quem escreve com as marcas de quem as lê, de forma que se gere um comum, coletivos, para pensarmos acerca das questões que nos atravessam e que nos convocam nesses espaços, ou quem sabe em outros. (DIMENSTEIN; MACEDO, 2009).

Abrir-se para esta nova perspectiva, pode nos levar por caminhos ainda não trilhados. Pode, ainda, ampliar nossos horizontes em relação ao que entendemos por educação. Podemos a partir disso, ousar pensar que educar, no fundo, pode ser uma forma de não saber: Que mesmo construindo modelos teóricos de extremo requinte e rigor, ainda continuamos pequenos diante da grandeza do mundo; Não saber que o universo é muito maior que todas as teorias juntas, e que a transcende as horas, os dias e anos, de uma forma que não sabemos explicar através de uma breve luz de consciência humana.

Desenvolver no cotidiano a capacidade de captar um vasto espaço entre a palavra e o silêncio. Andar pela imensidão e dizê-la. Mas não dizê-la como quem capta com as palavras a realidade que se apresenta. Mas dizê-la viva, com um corpo e em uma língua própria. Dizê-la fogo: que queima e desfaz. Deixar fluir um amor insistente pela vida, em nossos escritos, em nossas práticas de educação, em nossas reflexões. Aqui já não cabem segredos: tudo está posto. Imanente. Coisas da Terra...

\author{
Todas as coisas de que falo estão na cidade \\ entre o céu e a terra. \\ São todas elas coisas perecíveis \\ e eternas como o teu riso \\ a palavra solidária \\ minha mão aberta
}


ou este esquecido cheiro de cabelo

que volta

e acende sua flama inesperada

no coração de maio.

Todas as coisas de que falo são de carne

como o verão e o salário.

Mortalmente inseridas no tempo,

estão dispersas como o ar

no mercado, nas oficinas,

nas ruas, nos hotéis de viagem.

São coisas, todas elas,

cotidianas, como bocas

e mãos, sonhos, greves,

denúncias,

acidentes do trabalho e do amor. Coisas, de que falam os jornais

às vezes tão rudes

às vezes tão escuras

que mesmo a poesia as ilumina com dificuldade.

Mas é nelas que te vejo pulsando,

mundo novo,

ainda em estado de soluços e esperança.

(FERREIRA GULLAR) $^{3}$

As palavras não nos dizem. São um contorno vazio, em contraste com a imensidão que nos habita. Isto não é de todo, algo ruim. Afinal de contas, se elas estão vazias, podemos então preenchê-las com o que quisermos. As sensações, as cores, e as inquietações, que nos passam enquanto dizemos EU. A potência que é nossa mais premente virtualidade. A existência nômade. A territorialidade remota, a mais inóspita, os mais altos ares. A sequidão. Podemos então fazer um uso artístico das palavras. Escrever como quem pinta telas. "Somente um pensamento nascido da força, da coragem, da solidão, pode contemplar a potência.” (MOSÉ, 2011, p. 106).

3 Poema retirando do site:<http://versoeprosa.wordpress.com/tag/ferreira-gullar/>, acessado em 10/04/2013 
Pensar a palavra, e consequentemente a linguagem, pode nos servir para que possamos reinventar nossa relação com a mesma. E assim, quem sabe, criar meios mais inventivos de expressão, reinventar usos.

Da mesma forma que as palavras não estão, necessariamente, em correspondência com as coisas, à linguagem não está submetida, unicamente, à consciência e à comunicação. [...] Somente uma linguagem que não se sustentasse na identidade, no sujeito, na consciência, poderia contemplar os afetos. (MOSÉ, 2011, p. 131)

A partir de relações mais criativas e autênticas com a palavra, podemos então pensar em uma linguagem mais rica, mais dinâmica, potente e que expresse a exuberância que faz parte da vida, com a tragicidade que lhe é inerente, pois, "as palavras, quando assumidas como signo, como sinal, podem afirmar a vida. As palavras, quando não atadas à vinculação do sentido, da comunicação, do outro, são como molduras vazadas onde a vida se configura." (MOSÉ, 2011, p. 126).

Essa relação criativa exige de nós uma "juventude" e vitalidade, ousadia e desprendimento. E antes de tudo, o livre trânsito do desejo. Do desejo de afirmação da vida.

É somente a partir da afirmação da vida, a partir da inserção e não da negação do corpo e dos impulsos, que a linguagem pode ser reinventada.[...] Pensar uma linguagem mais afirmativa seria conceber, não uma linguagem mais próxima das coisas, mas uma que assumisse esta impossibilidade. [...] Ao contrário de dizer o que as coisas são, o que a linguagem pode fazer é se compor como um contorno ficcional e provisório, que busca não deter, mas manifestar a atividade interpretativa infinita que é a vida. [...] Somente uma interpretação que imponha um novo querer, ou seja, o querer a mudança, a provisoriedade, o tempo, pode permitir uma nova linguagem. (MOSÉ, 2011, p. 230)

E ousamos ir além. Ousamos propor uma escrita linguagem desejante. Que deseje como quem quer:

desejar uma moldura para uma imagem/retrato sem preencher o vazio, experimentando a visão do que se sente e escutando o que não é falado. [...] uma escrita que se experimenta estar entre caminhos. Nem em um lugar nem em outro. Grafias que expressam, às vezes sem pressa, às vezes quase "ao vivo". Invencionices. (ANDRADE; SPEGLICH, 2011)

Um desejo que não é uma contraposição da falta. Mas sim uma força que nos coloca em certa intensidade. Que nos arremessa a paraísos e pântanos. "Não é o desejo que se apoia nas necessidades; ao contrário, são as 
necessidades que derivam dos desejos: elas são contraproduzidas no real que o desejo produz. A falta é um contra efeito do desejo, depositada, arrumada, vacuolizada no real natural e social" (DELEUZE; GUATTARI, 2010, p. 44).

Nossas necessidades são então apenas um pós-texto do desejo. No fundo o desejo é tudo. É o grande movente, o que nos impulsiona para nossas potências, para outras vivências de corpo, de mundo. Pensar uma educação movida pelo desejo, pode significar, uma educação potencializada e potencializadora, movente e tocante. Pois, "Desejar é produzir na realidade. O real não é impossível; ao contrário, no real tudo é possível, tudo devém possível." (DELEUZE; GUATTARI, 2010, p. 44).

Produzir assim, uma educação que seja uma experimentação de si, que nos leve por devires outros. "O deserto, a experimentação sobre si mesmo é nossa única identidade, nossa única chance para todas as combinações que nos habitam." (DELEUZE; PARNET, 2004 p. 21). Não precisamos de uma educação que nos aloje em seus compartimentos protegidos, cobertos e seguro da diversidade caótica do mundo. Precisamos de uma educação que ao contrário, nos exponha a essas intempéries. Precisamos de uma educação que nos exponha aos caos criativo, que lide com o desordenado, que descontrói, que arranha. Os bons encontros se tecem com a facilidade de quem percorre uma trajetória em queda livre. Ficamos sem fôlego para alcançar todas as possibilidades que o universo escolar tem a nos o oferecer. Logo entendemos que o conhecimento é como o horizonte, sempre se alcança, e sempre se está por alcançar...

Vai-se entendendo um pouquinho e este entendimento pede um pouco mais outro que suscita ainda outro e mais outro, sem nunca estar findado. Paramos por lerdeza, por escassez de ar que as montanhas provocam ou ainda pela falta de ar que o oceano suscita. Mas poderíamos prosseguir sempre. Esta é a nossa imortalidade: as linhas de conexões que potencializamos com a vida. Não temos verdadeiramente mais nada e, no entanto, nada mais precisamos ter. (FELDENS, 2008, p. 32)

As conformações já estabelecidas não nos permitem vislumbrar os tantos possíveis que nos habitam... É preciso dispor-se aos encontros, às descobertas. E elas estão latentes no pensamento, em nossas escritas, silenciosas em potência. Mas é preciso não partir de terras já "conquistadas", um encontro requer a inocência do desconhecido. Um encontro requer a "Descobrir, encontrar, roubar, ao invés de resolver, reconhecer e julgar. Porque o reconhecimento é o contrário de um encontro" (DELEUZE; PARNET, 2004 p. 19). Descobrir-se outro, em pleno processor criativo. E mais que isso, descobrir que educação se faz no afeto, na doação de si. Uma educação feita com olhares, com gestos, com cuidados e pequenas felicidades que duram por toda uma vida. 
Somos acontecimentos, acontecimentos únicos, singulares, e são nos encontros que podemos aflorar em velocidades infinitas e atingir intensidades, percorrer novos caminhos e trilhar outras trajetórias que extrapolam nossa imaginação, nossa forma de ser.

Um deserto povoado. Cheio de encontros. Mas quantos devires negamos, ao querer reduzir a vida em fórmula ou teorias, ao querer calculá-la. É preciso abraçar a vida, abraçar nossas práticas diárias, nossas profissões, para que as dádivas do deserto nos sejam dadas, não sem nenhuma esforço, mas através do esforço do abraço, do querer, do se envolver....

As cores pulsam latentes, se não se tem cuidado vê-se tudo cinza, tons borrados, opacidades. A educação da contemporaneidade ainda teime em ver tudo em uma única e pálida cor...

Fugindo do caos da vida, tentamos colocar ordem no mundo, e consequentemente em nós, em nossas infinitas formas de ser e estar no mundo. Estabelecemos um gesto padronizado, uma forma correta de tocar o mundo, e o desviante não É, não poder Ser. Aprendemos a excluir. Mas ao excluir as variedades da existência, excluímos também os mundos possíveis, em nós. Já não somos múltiplos. Somos um, e se não somos, aprendemos a sê-lo. Aprendemos que a vida se faz estática, na unicidade. Aprendemos a não desviar. Já não somos os mesmos...

Os enquadramentos matam os devires, enquadramentos que não permitem que a diversidade tenha a vigor que lhe é de direito, diversidade que está presente no humano, mas que muitas vezes sufocamos e reduzimos em nossas produções, escritas e vivências, e assim, "por termos nos feito escravos de nossa soberania e de sua miséria perdemos a pluralidade da vida, a intensidade do intempestivo." (FELDENS, 2008, p. 59).

Nossa memória é fraca, não guardamos nas memórias os dias passados em verdes campos, com devires a aflorar por toda nossa pele. É preciso esforço pra lembrar que,

Somos uma tatuagem, uma marca em uma história de etapas, ciclos, períodos, estágios, idades. Somos este somatório de datações. Elas próprias arbitrariedades, balizas que vão produzindo calendários lineares e progressivos. Somos esses filhos bastardos de nossas conquistas. (FELDENS, 2008, p. 43)

Quando escapamos à linearidade, a vida nos é apresentada em um amontoado de estímulos e afetos, desordenados, desalinhados, caóticos. O mundo nos chega de forma indeterminada. O tempo nos prega peças. A vida se efetiva entre inúmeras idas e vindas, posses e perdas, dores e alegrias, em um turbilhão de cores e formas incomensuráveis, de emoções inomináveis, de gestos indescritíveis.

A noção de territorialização trata da produção de desejos vinculados as formações dos espaços, a territórios afetivos. E o desejo sempre latente. Desejar é em alguma medida sentir que carregamos o mundo em nós. 
Um mundo com toda a sua fauna e flora, todos os aromas, todas as cores, todos os paladares pulsam latentes na camada mais profunda de nossa pele, nas entranhas, contidas com as mãos, no crescer das unhas, em nossos suores.

Devires trazidos pelo vento de outros planetas, devires outros, seres potentes, vidas queimam como a mais potente chama da terra, terremotos e vulcões em erupção, animais selvagens, feras, bestas apocalípticas; todos eles latejam em nós, sem percebemos, pedem passagem, suas manadas passam de forma brutal, abalam nossos cotidianos, e nos gestos mais descuidados, nas palavras mais malditas se fazem reais.

Não Somos, portanto, nem maiores nem menores do que nós mesmos, somos o que inventamos para sermos e, nesta medida, somos potencialmente senhores da nossa vida. Potencialmente, não evidentemente. Com as potencialidades possíveis a latejar em nosso corpo que pede: pega a vida em tuas mãos, cria teus caminhos, habita tuas férteis terras. (FELDENS, 2008, p. 21)

Escrever é sempre um ato poético. Ao escrever, todos os gestos desenham poesias invisíveis pelo ar. Trajetórias tortuosas. Danças leves. Suaves movimentos. A vida transborda pelas entrelinhas.

Escrevemos na tentativa de eternizar o que não se vê. De captar o que nos acontece. Às vezes conseguimos fazer isso por um momento. Às vezes tudo nos escapa... "Assim, continuaram vivendo numa realidade escorregadia, momentaneamente capturada pelas palavras, mas que haveria de fugir sem remédio quando esquecessem os valores da letra escrita." (MÁRQUEZ, 2000, p. 79).

Já não há como fugir. Ao escrever estabelecemos uma conversação entre o dito e o não dito. $\mathrm{O}$ visto e o não visto. Com o finito. E, principalmente, com o infinito. Algumas conversações são intermináveis. E... E...

\section{Referências}

ANDRADE, Elenise Cristina Pires de; SPEGLICH, Érica. Imagens a fabular ambientes: desejos, perambulações, fugas, convites. Pesquisa em educação ambiental, UNESP, v. 6, n. 1, p. 123-137, 2011.

BAUDRILLARD, J. Cool Memories III - fragmentos: 1991-1995. São Paulo: Estação Liberdade, 2000.

DELEUZE, Gilles; GUATTARI, Félix. Mil platôs: Capitalismo e esquizofrenia. Rio de Janeiro: Ed. 34, 1997. v. 4.

DELEUZE, Gilles; GUATTARI, Félix. O Anti Édipo. Rio de Janeiro: Ed. 34, 2010.

DELEUZE, Gilles; PARNET, Claire. Diálogos. Lisboa: Editora Relógio D’água, 2004.

FELDENS, Dinamara G. Cartografias da ditadura e suas moralidades: os seres que aprendemos a ser. Maceió: EDUFAL, 2008. 
MACEDO, João Paulo; DIMENSTEIN, Magda. Escrita acadêmica e escrita de si: experienciando desvios. Mental, Barbacena, UNIPAC, v. 07, n. 12, p. 153-166, jun. 2009.

MÁRQUEZ, Gabriel García. Cem anos de Solidão. Rio de Janeiro: Record, 2000.

MOSÉ, Viviane. Nietzsche e a grande política da linguagem. 2. ed. Rio de Janeiro: Civilização Brasileira, 2011.

NIETZSCHE, F. Wilhelm. O nascimento da tragédia ou helenismo e pessimismo. São Paulo: Companhia das Letras, 2007.

\section{Endereço para correspondência:}

Dinamara Garcia Feldens

Rua Guilherme Alves, 801/405.

90680-001 Porto Alegre, RS, Brasil

$<$ dfeldens@hotmail.com>

Recebido em: maio/2014

Aceito em: dezembro/2014 